\title{
The Knowledge, Attitudes and Beliefs of the Healthcare Workers about Influenza Infection and Vaccination at a Public Hospital in Turkey
}

\author{
Ezgi Cülten', Deniz Özer Türk1', Arzu Erol2, Çı̆ğdem Özel² \\ 1 Department of Infectious Diseases and Clinical Microbiology, Atatürk City Hospital, Ballkesir, Turkey \\ 2 Infection Control Committee, Atatürk City Hospital, Balıkesir, Turkey
}

\begin{abstract}
Objective: Healthcare workers (HCWs) are at high risk in terms of influenza infection. Despite the fact that the HCWs were encouraged to be vaccinated against influenza as one of the prior target group, the vaccine coverage rates are low. This study aimed to assess HCWs' knowledge, attitude and beliefs against influenza infection and influenza vaccination at a public hospital in Turkey.

Materials and Methods: At a 1,100-bed hospital in which 2766 HCWs were employed, a face-to-face survey was conducted by four researchers. The information about demographic features, the awareness level of the potential risk of influenza infection on HCWs, influenza vaccination history and future thoughts about vaccination were obtained.

Results: In total, 1318 (47.6\%) HCWs participated in the study. 72.1\% ( $n=950)$ of respondents were female, and the mean age was 36.5. A hundred (7.6\%) HCWs had laboratory proved influenza infection history. Among the participants $14.9 \%(\mathrm{n}=256)$ did not consider themselves at high risk in terms of influenza infection, 32.2\% $(n=425)$ of respondents claimed that they did not have enough knowledge concerning protective precautions against influenza infection, and 55.5\% (n=731) of HCWs have never received influenza vaccine. Only 27 (2\%) HCWs got vaccinated against influenza, annually. Leading reasons for non-vaccination were disbelief in personal need (40.1\%) and disbelief in beneficial value (36.5\%) of influenza vaccine. The $81.9 \%(n=1079)$ of HCWs decided not to receive influenza vaccine during the 2018-2019 influenza season.

Conclusion: In conclusion, the vaccination rate of HCWs was too low, and the risk of influenza infection was being underestimated. There were misconceptions related to the influenza vaccine. Urgent action is needed to be taken to improve this situation.

Keywords: healthcare workers, influenza vaccination; influenza infection and healthcare workers; influenza survey; misconceptions related to influenza vaccine; vaccines and occupational health.

Abbreviations: HCW, healthcare worker; WHO, World Health Organization; CDC, Centers for Disease Control and Prevention; ILI, influenza-like infection
\end{abstract}

\section{INTRODUCTION}

S easonal influenza is an important cause of mortality, particularly in immunocompromised and elderly patients, children, pregnant and postpartum women. Iuliano et al. estimated that each year 291,243 to 645,832 deaths are attributed
Corresponding Author:

Ezgi Cülten

E-mail:

ezgioztop@gmail.com

Received: June 26, 2019

Accepted: September 12, 2019

Published: October 7, 2019

\section{Suggested citation:}

Gülten E, Özer Türk D, Erol A, Özel D. The Knowledge, Attitudes and Beliefs of the Healthcare Workers about Influenza Infection and Vaccination at a Public Hospital in Turkey. Infect Dis Clin Microbiol 2019; 2: 87-96.

DOI: $10.36519 / \mathrm{idcm} .2019 .19013$ 
to seasonal influenza (1). Turkey is located in the northern hemisphere; therefore, the majority of the influenza cases occur between October and April.

Regarding knowledge, attitude and practice (KAP) of HCWs, WHO and CDC recommend taking droplet precautions in case of a patient who has probable or proven influenza infection and vaccination of HCWs against influenza as the core element of preventive and control measures $(2,3)$. Vaccination of HCWs against influenza is necessary not only to protect HCWs and decrease sickness absenteeism but also to prevent nosocomial transmission from even asymptomatic personnel to their patients $(4,5)$. Beyond these main purposes, HCWs are role models to influence public opinion and to direct their patients for vaccination.

Turkish Ministry of Health has been providing freely available influenza vaccine for HCWs since 2004 and promoting onsite vaccination. Generally, vaccines are available in October, and volunteer HCWs are being vaccinated by infection control committees and/or occupational health departments. Nevertheless, vaccination coverage among HCWs remained lower than 20\% in Turkey and exceeded only $40 \%$ even during pandemic influenza in 2009 $(6,7)$.

A few published studies are investigating the dynamics of Turkish HCWs' unwillingness to receive influenza vaccine. In these studies, concerns about side effects and disbelief in beneficial value were

\section{HIGHLIGHTS}

- $14.9 \%$ of HCWs didn't take account of influenza infection as an occupational risk.

- The ratio of never vaccinated HCWs against influenza was too high: 55.5\%

- The ratio of annually vaccinated HCWs against influenza was too low: $2 \%$

- $32.2 \%$ of HCWs didn't have adequate knowledge regarding droplet precautions.

- $36.5 \%$ of HCWs had doubts about effectiveness of influenza vaccine. the most common addressed reasons for non-vaccination (8-10). At our institution, only 8 (0.03\%) of 2600 HCWs were vaccinated against influenza during the 2017-2018 season. Therefore, this KAP survey was designed to reveal the underlying causes of low vaccination rate and to plan the future action to take at an organizational level to motive HCWs to be vaccinated against influenza.

\section{MATERIALS AND METHODS}

In our institution, there were 1100 patient beds and 2766 HCWs as of 1st September 2018. A faceto-face survey was conducted by four researchers between 1st September 2018 and 1st October 2018. The participants were asked for: i) demographic data including age, sex, occupation and duration of work at healthcare sector; ii) influenza infection history, perceived risk of influenza infection, evaluating the adequacy and the source of their knowledge towards taking protective precautions against influenza infection; iii) influenza vaccination history, the reasons of non-vaccination and future thoughts about influenza vaccination. The history of laboratory-confirmed influenza refers to the past flu of which the cause was determined to be an influenza virus with rapid tests and/or molecular techniques. Whenever possible, participants were allowed to select more than one choices.

The sample size was calculated to be 191 HCWs at minimum, via chi-square goodness of fit test $(\alpha=0.05,95 \%$ CI ). The questionnaire was performed among as many participants as the researchers were able to reach to prevent possible selection bias and balance the number of vaccine defender/ opponent HCWs. The HCWs were grouped in four categories, A (physicians), B (nurses, pharmacists, psychologists, biologists, dieticians and physiotherapists), C (technicians, security, laundry workers, cafeteria workers and other ancillary staff), D (administrators, officers and secretaries).

\section{Statistical analyses}

Data was gathered and analyzed via the Statistical Package for Social Sciences version 24 (IBM SPSS) software. For intergroup comparison of categorical data Pearson chi-square, Fisher's exact test and chi-square for trend analyses were chosen. Mann 
Whitney U and Kruskal Wallis $\mathrm{H}$ tests were used to compare variables between different groups. $\mathrm{P}<0.05$ value was considered statistically significant and indicated by an asterisk $\left({ }^{*}\right)$.

\section{RESULTS}

In total, 1318 (47.6\%) of 2766 HCWs participated in the survey. Nine hundred and fifty $(72.1 \%)$ of participants were female. The mean age and the mean duration of work were 36.5 years and 12.1 years, respectively. Demographic features of the study population are listed in table 1 . Total number of HCWs from group A to D were 267, 1068, 1023 and 408, respectively.

From group A to D, the rate of HCWs who had laboratory-confirmed influenza infection history was 6.5\% (9/139), $11.1 \%$ (64/579), 5\% (18/363) and 3.8\% (9/237), respectively. In total, $7.6 \%(\mathrm{n}=100)$ of respondents experienced an influenza infection. The past history of influenza among group B was higher than the other groups $(p<0.001)$.

In total, $14.9 \%(\mathrm{n}=196)$ of HCWs did not consider themselves at high risk in terms of influenza infection. Four hundred and twenty-five (32.2\%) participants claimed that they did not have adequate knowledge to take protective precautions against influenza infection. Of remaining 893 (67.8\%) HCWs, participants in group A (54\%) and B (49.1\%) referred college lectures as their source of information regarding protective precautions against influenza infection. On the other hand, knowledge of HCWs in groups C (41\%) and D (40.9\%) were obtained from in-hospital educational interventions. HCWs who feel qualified to apply control measurements were at the healthcare sector for a longer duration $(13.69 \pm 9.01$ years vs $8.8 \pm 7.4$ years, $p<0.001)$. Table 2 summarizes the data about perceived risk and the source of information to take protective precautions against influenza infection.

Seven hundred and thirty-one (55.5\%) participants have never received influenza vaccine before. Never vaccinated HCWs' The mean duration of work was less among the HCWs, who never vaccinated than the HCWs who have received one or more doses of influenza vaccine before $(10 \pm 1.4$ vs $16.6 \pm 8.5$, p<0.001). Only $27(2 \%)$ HCWs got vaccinated against influenza, annually. Two prominent reasons specified for non-vaccination were disbelief in personal need (40.1\%) and disbelief in protective effect (36.5\%) of influenza vaccination. Vaccination history and reasons of non-vaccination were presented in table 3.

In total, 567 (43\%) HCWs claimed that influenza vaccine causes harm on the human body. Only, 333 (58.7\%) of these HCWs could declare one or more remarkable points. The most common side effects that were declared were flu-like illness (55.5\%), fever $(11.7 \%)$ and allergic reaction (10.2\%), followed by malaise (5.7\%), immunosuppression (5.7\%), local reactions at the injection site (4.2\%) and Guillain-Barré Syndrome (2.7\%). There was no statistical significance between the frequencies of the side effects $(p>0.05)$.

From group A to D, the number of HCWs who declared an intention to get vaccinated during 20182019 influenza season was 47 (33.8\%), 54 (9.3\%), 93 $(25.6 \%)$ and $38(16 \%)$, respectively. The other participants were either resistant ( $\mathrm{n}=1079,81.9 \%$ ) or confused $(n=7,0.5 \%)$. Participants in groups $A$ and $C$ were eager to receive the upcoming season's influenza vaccine $(\mathrm{p}<0.001)$. In groups A to $\mathrm{D}, 6 / 9(66.7 \%)$, 9/64 (14.1\%), 7/18 (38.9\%) and 4/9 (44.4\%) respondents who had influenza infection history were willing to get vaccinated. In group A, the history of past influenza infection was found to be associated with the intention of future influenza vaccination $(\mathrm{p}=0.007)$.

\section{DISCUSSION}

Seasonal influenza is a global health problem. HCWs are assumed to be the main reservoir to transmit influenza virus at healthcare settings (11). In addition to preventing HCWs from influenza infection, vaccinating HCWs against influenza was shown to decrease patients' all-cause mortality and influenza-like infection (ILI) rates $(12,13)$. Turkish Ministry of Health promotes HCWs' influenza vaccination by providing freely available inactivated influenza vaccine and each facility decides and conducts its own campaign. In a recent review, the lowest and the highest vaccination rates of HCWs 
Influenza Survey Study

Table 1. Demographic features of participants

\begin{tabular}{|c|c|c|c|c|c|}
\hline & Group A & Group B & Group C & Group D & Total \\
\hline \multicolumn{6}{|l|}{ No. respondents/ } \\
\hline total no. (\%) HCWs & 139/267 (52\%) & $579 / 1068(54.2 \%)$ & $363 / 1023(35.5 \%)$ & $237 / 408$ (58\%) & $1318 / 2766(47.6 \%)$ \\
\hline \multicolumn{6}{|l|}{ Age } \\
\hline Mean (SD) & $42.1(9.1)$ & $36.1(8.3)$ & $36.3(8.4)$ & $34.16(7.4)$ & $36.5(8.5)$ \\
\hline Median (min-max) & $41(24-68)$ & $38(19-58)$ & $36(19-60)$ & $34(20-57)$ & $37(19-68)$ \\
\hline OR $(95 \% \mathrm{Cl})$ & $0.9(0.89-0.94)^{*}$ & $1(0.99-1.02)^{\star}$ & $1(0.99-1.02)^{*}$ & $1(1.02-1.06)^{*}$ & \\
\hline \multicolumn{6}{|l|}{ Gender } \\
\hline Female $(n / \%)$ & $48(34.5 \%)$ & $504(87 \%)$ & $202(55.6 \%)$ & $196(82.7 \%)$ & $950(72.1 \%)$ \\
\hline Male (n/\%) & $91(65.5 \%)$ & 75 (13\%) & $161(44.4 \%)$ & $41(17.3 \%)$ & $368(27.9 \%)$ \\
\hline OR $(95 \% \mathrm{Cl})$ & $0.2(0.11-0.24)^{*}$ & $4.4(3.32-5.86)^{\star}$ & $0.4(0.27-0.45)^{\star}$ & $2(1.45-2.97)^{*}$ & \\
\hline \multicolumn{6}{|c|}{ Years of work at health care sector } \\
\hline Mean (SD) & $17.1(8.9)$ & $15(9.1)$ & $7.7(6.3)$ & $8.9(7.1)$ & $12.1(8.8)$ \\
\hline Median (min-max) & $17(0.1-41)$ & $15(0.1-40)$ & $6(0.1-33)$ & $7(0.5-39)$ & $10(0.1-41)$ \\
\hline OR (95\% Cl) & $0.9(0.92-0.95)^{\star}$ & $0.9(0.92-0.95)^{*}$ & $1.1(1.08-1.12)^{*}$ & $1(1.04-1.08)^{\star}$ & \\
\hline
\end{tabular}

${ }^{*} \mathrm{p}<0.001$

Table 2. Perceived risk and the origin of information to take protective precautions against influenza infection

\begin{tabular}{|c|c|c|c|c|c|}
\hline & Group A (n/\%) & Group B (n/\%) & Group C (n/\%) & Group D (n/\%) & Total $(n / \%)$ \\
\hline \multicolumn{6}{|c|}{ HCWs are at high risk of influenza infection } \\
\hline I agree & $128(92.1 \%)$ & $539(93.1 \%)$ & $267(73.6 \%)$ & $188(79.3 \%)$ & $1122(85.1 \%)$ \\
\hline I disagree & $11(7.9 \%)$ & $40(6.9 \%)$ & $96(26.4 \%)$ & $49(20.7 \%)$ & $196(14.9 \%)$ \\
\hline OR $(95 \% \mathrm{Cl})$ & $2.2(1.15-4.09)^{\star}$ & $3.6(2.5-5.2)^{\star}$ & $0.3(0.24-0.44)^{*}$ & $0.6(0.42-0.87)^{*}$ & \\
\hline \multicolumn{6}{|c|}{ I have enough knowledge to take protective precautions against influenza infection } \\
\hline No & $37(26.6 \%)$ & $138(20,4 \%)$ & $176(48,5 \%)$ & $94(39,7 \%)$ & $425(32,2 \%)$ \\
\hline Yes & $102(73.4 \%)$ & $461(79,6 \%)$ & $187(51,5 \%)$ & $143(60,3 \%)$ & $893(67,8 \%)$ \\
\hline OR $(95 \% \mathrm{Cl})$ & $1.4(0.91-2.01)^{*}$ & $2.8(2.16-3.56)^{*}$ & $0.4(0.29-0.48)^{*}$ & $0.7(0.5-0.9)^{*}$ & \\
\hline \multicolumn{6}{|c|}{ If yes, the source of my information is;*** } \\
\hline In-hospital educations & $25(18 \%)$ & $237(40,9 \%)$ & $149(41 \%)$ & $97(40,9 \%)$ & $508(38,5 \%)$ \\
\hline OR $(95 \% \mathrm{Cl})$ & $0.3(0.2-0.5)^{\star}$ & $1.2(0.96-1.5)^{\star}$ & $1.2(0.9-1.48)^{*}$ & $1.1(0.85-1.5)^{*}$ & \\
\hline Lectures at college & $75(54 \%)$ & $284(49,1 \%)$ & $21(5,8 \%)$ & $23(9,7 \%)$ & $403(30,6 \%)$ \\
\hline OR $(95 \% \mathrm{Cl})$ & $3(2.13-4.35)^{\star}$ & $5(3.89-6.47)^{\star}$ & $0.1(0.06-0.15)^{\star}$ & $0.2(0.13-0.31)^{\star}$ & \\
\hline Other collegues ${ }^{\star \star}$ & $6(4,3 \%)$ & $29(5 \%)$ & $17(4,7 \%)$ & $10(4,2 \%)$ & $62(4,7 \%)$ \\
\hline Social media & $7(5 \%)$ & $80(13,8 \%)$ & $12(3,3 \%)$ & $9(3,8 \%)$ & $108(8,2 \%)$ \\
\hline OR $(95 \% \mathrm{Cl})$ & $0.6(0.26-1.24)^{*}$ & $4.1(2.6-6.36)^{\star}$ & $0.3(0.17-0.57)^{\star}$ & $0.4(0.2-0.79)^{*}$ & \\
\hline My own research & $24(17,3 \%)$ & $108(18,7 \%)$ & $22(6,1 \%)$ & $28(11,8 \%)$ & $182(13,8 \%)$ \\
\hline OR (95\% Cl) & $1.4(0.84-2.16)^{\star}$ & $2.1(1.5-2.84)^{\star}$ & $0.3(0.2-0.51)^{*}$ & $0.8(0.53-1.24)^{*}$ & \\
\hline
\end{tabular}

${ }^{*} \mathrm{P}<0.001 ;{ }^{* *} \mathrm{P}>0.05 ;{ }^{* * *}$ More than one choice could be selected by participants. 
Table 3. Influenza vaccination history and reasons of non-vaccination

\begin{tabular}{|c|c|c|c|c|c|}
\hline & Group A (n/\%) & Group B (n/\%) & Group C (n/\%) & Group D (n/\%) & Total (n/\%) \\
\hline \multicolumn{6}{|l|}{ I have received influenza vaccine before } \\
\hline Yes & $89(64 \%)$ & $280(48.4 \%)$ & $128(35.3 \%)$ & $90(38 \%)$ & $587(44.5 \%)$ \\
\hline No & $50(36 \%)$ & $299(51.6 \%)$ & $235(64.7 \%)$ & $147(62 \%)$ & $731(55.5 \%)$ \\
\hline OR $(95 \% \mathrm{Cl})$ & $2.4(1.69-3.51)^{\star}$ & $1.3(1.06-1.64)^{\star}$ & $0.6(0.46-0.76)^{\star}$ & $0.7(0.54-0.96)^{*}$ & \\
\hline \multicolumn{6}{|l|}{ If yes, number of vaccines received; } \\
\hline $1^{\star \star}$ & $33(23.7 \%)$ & $138(23.8 \%)$ & 74 (20.4\%) & $48(20.3 \%)$ & $293(22.3 \%)$ \\
\hline $1-5^{\star *}$ & $44(31.7 \%)$ & $124(21.4 \%)$ & $36(9.9 \%)$ & $35(14.8 \%)$ & $239(18.1 \%)$ \\
\hline$>5^{\star \star}$ & $4(2.9 \%)$ & $13(2.3 \%)$ & $8(2.2 \%)$ & $3(1.3 \%)$ & $28(2.1 \%)$ \\
\hline Annually** & $8(5.7 \%)$ & $5(0.9 \%)$ & $10(2.8 \%)$ & $4(1.6 \%)$ & $27(2 \%)$ \\
\hline \multicolumn{6}{|l|}{ I never received influenza vaccine because;*** } \\
\hline I was rushed for time & $9(18 \%)$ & $5(1.6 \%)$ & $6(2.5 \%)$ & $10(7 \%)$ & $30(4.1 \%)$ \\
\hline OR $(95 \% \mathrm{Cl})$ & $3.8(1.71-8.51)^{\star}$ & $0.3(0.1-0.65)^{\star}$ & $0.7(0.26-1.61)^{*}$ & $2.3(1.08-5.06)^{\star}$ & \\
\hline I didn't know where to find the vaccine & $1(2 \%)$ & $5(1.6 \%)$ & $31(13.2 \%)$ & $3(2 \%)$ & $40(5.1 \%)$ \\
\hline OR $(95 \% \mathrm{Cl})$ & $0.2(0.03-1.55)^{\star}$ & $0.2(0.07-0.45)^{*}$ & $9.8(4.62-20.83)^{*}$ & $0.4(0.11-1.18)^{\star}$ & \\
\hline I didn't need to get vaccinated ${ }^{\star *}$ & $28(56 \%)$ & $125(41.8 \%)$ & $84(35.7 \%)$ & $56(38 \%)$ & $293(40.1 \%)$ \\
\hline The vaccine wouldn't protect me from infection & $11(22 \%)$ & $137(45.8 \%)$ & $73(31.1 \%)$ & $46(31.3 \%)$ & $267(36.5)$ \\
\hline OR $(95 \% \mathrm{Cl})$ & $0.3(0.17-0.58)^{*}$ & $1.5(1.11-1.9)^{\star}$ & $1(0.73-1.33)^{\star}$ & $1(0.66-1.34)^{\star}$ & \\
\hline I was afraid of the side effects & $5(3.6 \%)$ & $43(14.4 \%)$ & $48(20.4 \%)$ & $31(13.1 \%)$ & $127(17.3 \%)$ \\
\hline OR $(95 \% \mathrm{Cl})$ & $0.3(0.13-0.8)^{*}$ & $0.6(0.43-0.92)^{*}$ & $1.7(1.15-2.47)^{\star}$ & $1.5(1-2.38)^{\star}$ & \\
\hline Other reasons ${ }^{\star \star}$ & $1(2 \%)$ & $8(2.6 \%)$ & $2(0.8 \%)$ & $3(2 \%)$ & 14 (1.9\%) \\
\hline
\end{tabular}

${ }^{*} \mathrm{P}<0.001 ;{ }^{* *} \mathrm{P}>0.05 ;{ }^{* \star *}$ More than one choice could be selected by participants.

against influenza were 3.7\% in Vietnam and 85.7\% in Japan, respectively (14). In Turkey, this rate was reported between $11.3 \%$ to $18.4 \%(7,9)$. The in fection control committee and the occupational health department declared that only $8(0.3 \%)$ of 2600 HCWs at our hospital got vaccinated against influenza during the 2017-2018 influenza season. When analysed in-depth, it was concluded that two major reasons constituted this devastating problem: absence of a national adult and HCW immunization program and anti-vaccine campaigns on social media. By the end of January 2019, only 137 (5\%) of 2766 HCWs at our facility received influenza vaccine. While previous studies reported the ratio of annually vaccinated HCWs between $66 \%$ to $81 \%$, only $2 \%$ of participants in the present study have received influenza vaccine annually $(11,15)$. Besides, despite about 12 years of work experience in the healthcare sector, $55.5 \%$ of respondents have never received a single shot of influenza vaccine. The rate of never vaccination among HCWs were reported from $51.3 \%$ to $69.8 \%$ in various studies in Turkey, whereas this rate was reported from 4.4 to $16.7 \%$ in other countries $(6,15-18)$. In a study from Greece, the rate of never vaccinated HCWs was reported as $60 \%$ (19). To increase HCWs' vaccination rates, campaigns which combine education, freely available vaccination, vaccination extended over a period of time, introductory activities and rewards were suggested to be effective (20-22). In addition, many reports advised mandatory vaccination of the HCWs against influenza $(23,24)$. To our knowledge, no campaigns have been implemented at our facility to date. It is clear that urgent action is needed to be taken.

Our survey revealed that the sources of information regarding protective precautions were college 
lectures and hospital educations. The effect of personal research, social media and communication with peers were negligible.

Although the order varies in different reports, in concordance with our findings, the leading three reasons for not being vaccinated were disbelief in personal need, doubts related to efficacy and side effects $(10,25,26) .234$ (17.8\%) of our participants declared their concerns but could not give evidence for the side effects. The best-known side effects of influenza vaccine are local reactions on injection site, headache, fever, nausea and muscle aches. Contrary to popular belief, the influenza vaccine does not cause flu and immunosuppression. Also, allergic reactions and Guillain-Barré Syndrome are infrequent (27). It was reported that, in the case of influenza vaccination, the respiratory tract is replaced by other pathogens, and the number of ILIs per year does not decrease (28). This could be the main reason for HCWs at our facility to question the effectiveness of the influenza vaccine. To fill the gap of misconceptions related to the effects of influenza infection over HCWs and efficacy and safety of the influenza vaccine, adapting the accurate information to educational interventions should be useful.

Myers et al. reported that $8.1 \%$ of HCWs were not considering themselves at high risk in terms of influenza infection (29). In our study, this ratio was also high, $14.9 \%, 20.7 \%$ and $26.4 \%$ in all group, group D and group C, respectively. In terms of self-reporting of adequate knowledge about the protective precautions against influenza infection, groups $C$ and $\mathrm{D}$ were less confident, and these two groups had the lowest immunization coverage against influenza. Therefore, groups $C$ and D were of top priority to take urgent action to prevent influenza infection.

During our survey period, some of the participants reported ILI history but only $7.6 \%$ documented influenza infection. It was estimated that $25 \%$ of HCWs were infected with influenza annually, and HCWs represent $20 \%$ to $30 \%$ of laboratory-confirmed influenza cases $(17,30)$. It was compromised that, in real-life settings, the number of HCWs at our facility who were once infected with influenza was higher and due to lack of being tested and underestimated the risk of infection, the reporting was poor. Compared to other groups, more HCWs in group B had influenza infection history, because vaccination rate and knowledge towards taking protective precautions against influenza infection were less than expected in this group of HCWs who were supposed to interact with inpatients who had probable/proven influenza infection more frequently.

Surprisingly, HCWs who had influenza infection history were not intended to receive an influenza vaccine in the future. Christini et al. also found that ILI did not increase the intention to be vaccinated against influenza (11).

\section{Study limitations and strengths}

By conducting the survey face-to-face and efforts to reach every personnel, $47.6 \%$ of HCWs at our facility participated in our study. This high participation rate, which reduced the probability of selection bias, was the major strength of our study. The awareness of the HCWs who were vaccinated could be higher to participate in the survey. We did not ask for any documentation about vaccination; we relied on the recall of the HCWs.

In conclusion, the vaccination rate of HCWs at our facility was too low, the risk of influenza infection was being underestimated and there were misconceptions related to the influenza vaccine. The results revealed that, apart from the previous studies, there is a huge diversity between developing and developed countries in terms of HCWs' knowledge and attitude towards influenza vaccination and taking protective precautions against influenza infection. Since in-house educational interventions were found to be the main correctible factor in our study, to increase vaccination rates, improving the quality and the number of hospital educations and conducting dedicated and coordinated campaigns should be of top priority. 
Ethics Committee Approval: The Ethical Committee of Balıkesir University, Turkey, approved the study with the decision number of 2018/179.

Informed Consent: Personal willing to respond to the survey was accepted as informed consent.

Peer-review: Externally peer-reviewed

Author Contributions: Concept - E.G., D.Ö.T, A.E., Ç.Ö.; Supervision - E.G.; Resources - E.G., D.Ö.T, A.E., Ç.Ö.; Materials - E.G., D.Ö.T, A.E., Ç.Ö.; Data Collection and/or Processing - E.G., D.Ö.T, A.E., Ç.Ö.; Analysis and/or Interpretation - E.G., D.Ö.T, A.E., Ç.Ö.; Literature Search - E.G., D.Ö.T, A.E., Ç.Ö.; Writing Manuscript - E.G., Ö.D.; Critical Reviews - E.G., D.Ö.T, A.E., Ç.Ö.
Acknowledgements: We are thankful to the respondents and the hospital administrators for their involvement and support for the organization of the study.

Conflict of Interest: The authors have no conflict of interest to declare.

Financial Disclosure: The authors declared that this study has received no financial support.

Note: This study had been presented as a poster presentation in 29th European Congress of Clinical Microbiology and Infectious Diseases (ECCMID) in Amsterdam, Netherlands, 13-16 April 2019.

\section{REFERENCES}

1 Iuliano AD, Roguski KM, Chang HH, Muscatello DJ, Palekar R, Tempia S, et al. Estimates of global seasonal influenza-associated respiratory mortality: a modelling study. Lancet 2018; 391: 1285-1300. doi:10.1016/S0140-6736(17)33293-2.

2 World Health Organization Regional Office for Europe. Vaccination 2019. (cited 2019 Feb 16). Available from: URL: http:// www.euro.who.int/en/health-topics/communicable-diseases/ influenza/vaccination.

3 Centers for Disease Control and Prevention. Prevention Strategies for Seasonal Influenza in Healthcare Settings | CDC 2018. (cited 2019 Feb 16). Available from: URL: https://www.cdc.gov/ flu/professionals/infectioncontrol/healthcaresettings.htm

4 Chan SS. Does vaccinating ED health care workers against in fluenza reduce sickness absenteeism? Am J Emerg Med 2007; 25: 808-11. doi:10.1016/j.ajem.2007.02.002.

5 Wendelboe AM, Avery C, Andrade B, Baumbach J, Landen MG. Importance of employee vaccination against influenza in preventing cases in long-term care facilities. Infect Control Hosp Epidemiol 2011; 32: 990-97. doi:10.1086/661916.

6 Ormen B, Türker N, Vardar I, Kaptan F, El S, Ural S, et al. [Attitudes and side effects related to pandemic influenza A (H1N1) vaccination in healthcare personnel]. Mikrobiyol Bul 2012; 46: 57-64.

7 Öncel EK, Büyükcam A, Cengiz AB, Kara A, Ceyhan M, Doğan BG. Hekim ve hemşire dışındaki hastane personelinin mevsimsel grip aşısı ile ilgili bazı bilgilerinin, görüşlerinin ve tutumlarının değerlendirilmesi. Cocuk Enfeksiyon Derg 2015; 9: 68-75. doi:10.5152/ced.2015.2009.

8 Ozkaya Parlakay A, Abdulmumin AH, Kara A, Cengiz AB, Ince E, Ciftci E, et al. Prior to Influenza Pandemics 2009 Evaluation of Views of Health Care Staff. Journal Pediatr Infect 2012; 6: 37-39. doi:10.5152/ced.2012.09.

9 Unver Ulusoy T, Tanyel E. Knowledge Levels, Perceptions, Attitudes, and Behaviors Regarding Flu, Common Cold, Influenza
Vaccine and Antimicrobial Usage Among Physicians Working at a University Hospital. Klimik J 2017; 30: 71-77. doi:10.5152/ kd.2017.18.

10 Gurbuz Y, Tutuncu EE, Sencan I, Sendag E, Callak F, Sevinc G, et al. Study on the willingness of health care workers to receive an influenza vaccination during the 2009 Influenza A (H1N1) pandemic. Pamukkale Med J 2013; 6: 12-17. doi:10.5505/ ptd.2013.07078

11 Christini AB, Shutt KA, Byers KE. Influenza Vaccination Rates and Motivators Among Healthcare Worker Groups. Infect Control Hosp Epidemiol 2007; 28: 171-77. doi:10.1086/511796.

12 Ahmed F, Lindley MC, Allred N, Weinbaum CM, Grohskopf L. Effect of influenza vaccination of healthcare personnel on morbidity and mortality among patients:systematic review and grading of evidence. Clin Infect Dis. 2014; 58(1): 50-57. doi: 10.1093/cid/cit580.

13 Genovese C, Picerno IAM, Trimarchi G, Cannavò G, Egitto G, Cosenza B, et al. Vaccination coverage in healthcare workers: a multicenter cross-sectional study in Italy. J Prev Med Hyg. 2019; 60(1): E12-E17. doi: 10.15167/2421-4248/jpmh2019.60.1.1097.

14 To KW, Lai A, Lee KCK, Koh D, Lee SS. Increasing the coverage of influenza vaccination in healthcare workers: review of challenges and solutions. J Hosp Infect 2016; 94: 133-42. doi:10.1016/j.jhin.2016.07.003.

15 Tuckerman JL, Collins JE, Marshall HS. Factors affecting uptake of recommended immunizations among health care workers in South Australia. Hum Vaccines Immunother 2015; 11: 70412. doi:10.1080/21645515.2015.1008886.

16 Ballestas T, McEvoy SP, Doyle J. Co-ordinated approach to healthcare worker influenza vaccination in an area health service. J Hosp Infect 2009; 73: 203-09. doi:10.1016/j. jhin.2009.07.028.

17 Boey L, Bral C, Roelants M, De Schryver A, Godderis L, Hoppenbrouwers K, et al. Attitudes, believes, determinants and organ- 
isational barriers behind the low seasonal influenza vaccination uptake in healthcare workers - A cross-sectional survey. Vaccine 2018; 36: 3351-58. doi:10.1016/j.vaccine.2018.04.044.

18 Sari T, Temocin F, Kose H. Attitudes of Healthcare Workers Towards Influenza Vaccine. Klimik J 2017; 30: 59-63. doi:10.5152/ kd.2017.15.

19 Maltezou HC, Katerelos P, Poufta S, Pavli A, Maragos A, Theodoridou M. Attitudes toward mandatory occupational vaccinations and vaccination coverage against vaccine-preventable diseases of health care workers in primary health care centers. Am J Infect Control 2013; 41: 66-70. doi:10.1016/j. ajic.2012.01.028.

20 Song JY, Park CW, Jeong HW, Cheong HJ, Kim WJ, Kim SR. Effect of A Hospital Campaign for Influenza Vaccination of Healthcare Workers. Infect Control Hosp Epidemiol 2006; 27: 612-17. doi:10.1086/504503.

21 Lindley MC, Horlick GA, Shefer AM, Shaw FE, Gorji M. Assessing State Immunization Requirements for Healthcare Workers and Patients. Am J Prev Med 2007; 32: 459-65. doi:10.1016/j. amepre.2007.02.009.

22 Prematunge C, Corace K, McCarthy A, Nair RC, Pugsley R, Garber $\mathrm{G}$. Factors influencing pandemic influenza vaccination of healthcare workers-A systematic review. Vaccine 2012; 30: 4733-43. doi:10.1016/j.vaccine.2012.05.018.

23 Ottenberg AL, Wu JT, Poland GA, Jacobson RM, Koenig BA, Tilburt JC. Vaccinating health care workers against influenza: the ethical and legal rationale for a mandate. Am J Public Health 2011; 101: 212-16. doi:10.2105/AJPH.2009.190751.

24 van Delden JJM, Ashcroft R, Dawson A, Marckmann G, Upshur $\mathrm{R}$, Verweij MF. The ethics of mandatory vaccination against influenza for health care workers. Vaccine 2008; 26: 5562-66. doi:10.1016/j.vaccine.2008.08.002.

25 Ko K, Kim S, Kim SH, Son KY, Lee J, Lee DR. Knowledge, current status, and barriers toward healthcare worker vaccination among family medicine resident participants in a web-based survey in Korea. Korean J Fam Med 2017; 38: 21-27. doi:10.4082/ kjfm.2017.38.1.21.

26 Hulo S, Nuvoli A, Sobaszek A, Salembier-trichard A. Knowledge and attitudes towards influenza vaccination of health care workers in emergency services. Vaccine 2017; 35: 205-07. doi:10.1016/j.vaccine.2016.11.086.

27 Centers for Disease Control and Prevention. Flu Vaccine Safety Information. Quest Answ 2017. (cited 2019 Feb 16). Available from: URL: https://www.cdc.gov/flu/protect/vaccine/general. $\underline{h t m}$

28 Van Beek J, Veenhoven RH, Bruin JP, Van Boxtel RAJ, De Lange MMA, Meijer A, et al. Influenza-like illness incidence is not reduced by influenza vaccination in a cohort of older adults, despite effectively reducing laboratory-confirmed influenza virus infections. J Infect Dis 2017; 216: 415-24. doi:10.1093/ infdis/jix268.

29 Myers AL, Lantos J, Douville L, Jackson MA. Healthcare Worker Knowledge and Attitudes Regarding Influenza Immunization and Childhood Vaccination. Infect Control Hosp Epidemiol 2010; 31: 643-46. doi:10.1086/652777.

30 Kawana A, Teruya K, Kirikae T, Sekiguchi JI, Kato Y, Kuroda E, et al. "Syndromic surveillance within a hospital" for the early detection of a nosocomial outbreak of acute respiratory infection. Jpn J Infect Dis 2006; 59: 377-79. doi:10.1101/sqb.2008.73.032. 


\section{SUPLEMENT: EVALUATION OF HEALTHCARE WORKERS' KNOWLEDGE, ATTITUDES AND BELIEVES AGAINST INFLUENZA INFECTION AND INFLUENZA VACCINATION, QUESTIONNAIRE}

\section{Demographic data}

Age:

Gender:

Occupation:

The year of work at health care sector:

\section{Knowledge and practice regarding influenza infection and protective precautions}

1. Have you ever had flu of which the cause was determined to be influenza virus with laboratory results?
a. Yes
b. No

2. Do you think you have adequate knowledge regarding taking protective precautions against influenza infection?
a. Yes
b. No

3. If your answer was 'Yes' to previous question, please adress the source of your information. More than one choice can be selected.
a. In-hospital educational interventions
b. College lectures
c. My own research
d. Attraction with other collegues
e. Social media
f. Other (Specify)...

4. Do you think that in terms of influenza infection, are health care workers at higher risk because of their occupation?
a. Yes
b. No

\section{Attitudes towards influenza vaccination}

1. Have you ever been vaccinated against influenza?
a. Yes
b. No

2. If your answer was 'Yes' to previous question, how many times did you receive influenza vaccine?
a. 1
b. $1-5$
c. $>5$
d. I receive vaccine annually 
3. If you have never received influenza vaccine before, please address reason(s) for your nonvaccination status. More than one choice can be selected.
a. I was rushed for time
b. I didn't know where to find the vaccine
c. I didn't need to get vaccinated
d. The vaccine wouldn't protect me from infection
e. I was afraid of the side effects
f. Other (Specify)...

4. Do you think that influenza vaccine has significant side effects?
a. Yes
b. No

5. If your answer was 'Yes' to previous question, please point out these side effects.

6. Do you consider to get vaccinated during 2018-2019 influenza season?
a. Yes
b. No 